\title{
HÁ ENDOGENEIDADE NO ACESSO ÀS POLÍTICAS DE DESENVOLVIMENTO TECNOLÓGICO E EXPORTADOR NO BRASIL?*
}

\author{
Graziela Ferrero Zucoloto ${ }^{a}$ \\ Mauro Oddo Nogueira ${ }^{b}$ \\ Daniel da Silva Grimaldic \\ Flávio Lyrio Carneiro ${ }^{d}$
}

RESUMO: Este artigo analisa a relação entre três estudos realizados com o objetivo de avaliar políticas públicas selecionadas de apoio à exportação e ao desenvolvimento tecnológico, discutindo como incentivos governamentais podem resultar no apoio a agentes que já realizam as atividades a serem apoiadas. As políticas em questão se referem à promoção às exportações; a incentivos fiscais à pesquisa e desenvolvimento (P\&D) concedidos no âmbito da Lei do Bem; e à dinâmica das parcerias tecnológicas entre institutos de ciência e tecnologia (ICT) e empresas do setor de informática, desenvolvidas a partir dos créditos oferecidos pelo Fundo Setorial de Tecnologia da Informação (CT-Info). A partir dos resultados dessas três análises, observa-se a identificação de um quadro de endogeneidade decorrente de suas concepções e implementações que impede sua disseminação como veículos de dinamização da economia como um todo.

PALAVRAS-CHAVE: Exportação; tecnologia; políticas públicas.

CLASSIFICAÇÃO JEL: O2.

* Artigo recebido em 06/12/2011 e aprovado em 23/04/2013.

a Doutora em Economia pela Universidade Federal do Rio de Janeiro (UFRJ) e técnica de planejamento e pesquisa do Instituto de Pesquisa Econômica Aplicada (IPEA). Contato: graziela.zucoloto@ipea.gov.br.

b Doutor em Engenharia de Sistemas e Computação (UFRJ) e técnico de planejamento e pesquisa do IPEA. Contato: mauro.oddo@ipea.gov.br.

c Mestre em Economia pela Faculdade de Economia e Administração da Universidade de São Paulo (FEA/ USP) e economista do Banco Nacional de Desenvolvimento Econômico e Social (BNDES). Contato: grimaldi_daniel@yahoo.com.br.

d Estudante do Mestrado em Economia da Universidade de Brasília (UnB) e técnico de planejamento e pesquisa na Diretoria de Estudos e Relações Econômicas e Políticas Internacionais (Dinte) do IPEA. Contato: flavio.carneiro@ipea.gov.br. 


\section{ENDOGENEITY IN THE ACCESS OF TECHNOLOGICAL AND EXPORT POLICIES IN BRAZIL}

ABSTRACT: This paper analyses selected public policies that support exports and technological development. First it analyses selected instruments to promote exports, then the fiscal incentives to support R\&D and, at last, the technological partnership between science and technology institutes and enterprises of the computer industry. Finally, it analyses wheter the evaluated policies are able to achieve their objectives.

KEYWORDS: Exports; technology; public policy. 


\section{INTRODUÇÃO}

Os anos recentes da vida econômica brasileira têm sido marcados por uma postura mais ativa por parte do Estado, que resultou, entre outras ações, em incremento ao fomento das atividades produtivas. Argumenta-se que, ao estimularem determinados setores ou práticas empresariais, essas políticas sejam capazes, por efeitos de arraste ou de transbordamentos, de dinamizar a economia como um todo. Do ponto de vista instrumental, tais ações caracterizam-se basicamente pela oferta de créditos subsidiados (ou mesmo a fundo perdido) e pela concessão de benefícios fiscais.

Diante do atual contexto da economia mundial, a ação governamental concentra sua atenção em elementos integrados, considerados promotores fundamentais do dinamismo econômico: inserção qualificada no mercado internacional e desenvolvimento da capacidade de inovação, visando aumentar o valor agregado da produção. No sentido de impulsioná-los, dois desafios são colocados para os formuladores de políticas públicas: i) desenvolver instrumentos de incentivo que aumentem a propensão das empresas de inovarem e exportarem; e ii) facilitar a realização dessas atividades, aumentando, desse modo, a competitividade das empresas. Em outras palavras, criar instrumentos e mecanismos de atratividade que disseminem essas práticas através da estrutura produtiva do país, de modo a aumentar o contingente de empresas que as adotam; e oferecer benefícios que auxiliem as empresas que já o fazem a transformarem tais práticas em efetivas vantagens competitivas.

Este texto analisa, de forma associada, os resultados de três estudos sobre políticas de apoio à exportação e desenvolvimento tecnológico. Primeiramente, são analisados instrumentos selecionados de promoção das exportações: incentivos fiscais (drawback) e financeiros, a saber, Exim, do BNDES, e Proex, do Banco do Brasil (Grimaldi e Carneiro, 2010). A seguir, examinam-se os incentivos fiscais à pesquisa e desenvolvimento (P\&D) concedidos no âmbito da Lei do Bem (Zucoloto, 2010). Por fim, avalia-se a dinâmica das parcerias tecnológicas entre institutos de ciência e tecnologia (ICT) e empresas do setor de informática desenvolvidas a partir dos créditos oferecidos pelo Fundo Setorial de Tecnologia da Informação (CT-Info) (Nogueira, Kubota e Milan, 2011), componente do Fundo Nacional de Desenvolvimento Científico e Tecnológico (FNDCT).

Este trabalho tem por objetivo comparar os resultados alcançados pelos estudos mencionados, aprofundando o debate sobre políticas públicas no país. No processo de avaliação de políticas que, ao buscarem estimular atividades ou setores específicos, estabelecem mecanismos que selecionam os agentes econômicos que delas se beneficiarão, é de fundamental importância que se tenha em conta sua capacidade de permanecer acessível a todos os agentes para os quais são elegíveis. 
Conforme se verá, os estudos aqui considerados apontam sinais de que essas ações governamentais, em que pese seus resultados positivos, não vêm alcançando o objetivo de dinamizar a economia como um todo. Assim, após apresentar os resultados alcançados na análise de cada um dos instrumentos mencionados, na parte final discute-se em que medida as políticas avaliadas seriam capazes de atender a esse pressuposto, estimulando novos agentes a exportar e inovar no Brasil, e identificar a existência de possíveis características comuns a esses instrumentos e que seriam determinantes de um processo de endogenia em sua abrangência.

\section{INSTRUMENTOS DE INCENTIVO À EXPORTAÇÃO}

\subsection{INTRODUÇÃO}

Com o processo de abertura comercial, iniciado no final dos anos 1980, e diante das frustrações quanto ao pífio desempenho econômico brasileiro, que perdurou até o início dos anos 2000, as empresas brasileiras voltaram a enxergar nas exportações um componente estratégico para a diluição de riscos (por meio da diversificação de mercados) e para o ganho de competitividade (mediante aprendizado e ganhos de escala). Esse esforço de conquista do mercado internacional se intensificou especialmente após a desvalorização cambial de 1999.

Estimuladas por uma conjuntura internacional extremamente favorável (principalmente a partir de 2002), de acelerado crescimento do comércio internacional, baixa inflação e taxas de juros reais próximas a zero, ou negativas, nos principais países desenvolvidos, as exportações brasileiras atingiram o patamar de US\$ 198 bilhões, em 2008. Comparado ao total exportado em 2002, esse número equivale a uma taxa de crescimento real anual de aproximadamente $18,4 \%$, segundo dados do United Nations Commodity Trade Statistics Database (UNComtrade).

Assim como a estratégia das firmas, a política externa adotada pelo Brasil passou a dar maior importância à promoção das exportações. Consolidou-se, ao longo dos últimos dez anos, a visão de que a promoção das exportações deve ser o foco da política comercial. Atualmente, três instrumentos se destacam como importantes políticas para promover as exportações brasileiras. O primeiro é o drawback, um regime aduaneiro diferenciado que permite a importação de peças, componentes e matérias-primas com isenção ou suspensão de diversos tributos, desde que esses insumos sejam usados na fabricação de bens destinados à exportação. Esse é o instrumento mais abrangente, tendo apoiado mais de 2.900 empresas no ano de 2007. Os outros dois são as linhas de financiamento à exportação de bens e serviços oferecidos tanto pelo Banco do Brasil (BB) - o Programa de Financiamento às Exportações (Proex) - quanto pelo BNDES - o Exim. 
O drawback, o Proex e o Exim, tomados em conjunto, assistiram 3.162 empresas em 2007. Esse número é equivalente a mais de 15\% das firmas exportadoras naquele ano. Por isso, podem ser caracterizados como os maiores instrumentos públicos voltados à promoção das exportações. Diante disso, buscou-se responder à seguinte pergunta: qual é o perfil das empresas que mais têm feito uso destes três instrumentos?

A resposta possibilita que se avalie se o foco da política comercial tem sido congruente, na prática, com os objetivos aos quais ela se propõe. A partir do que se poderia chamar de "sinalizações" por parte do governo federal, três objetivos específicos foram considerados como mais relevantes na condução da política comercial brasileira: i) elevação do número de empresas da base exportadora, meta da Política de Desenvolvimento Produtivo (PDP) ${ }^{1}$; ii) aumento da sofisticação tecnológica da pauta comercial, tema recorrente nos discursos dos formuladores de políticas; e iii) estímulo às exportações de micro, pequenas e médias empresas (MPME) ${ }^{2}$.

Nesse estudo se procurou observar em que medida o drawback, o Proex e o Exim têm atendido a essas demandas.

\subsection{DESENHO DO ESTUDO}

O estudo se apoiou na consolidação de quatro bancos de microdados: i) a Relação Anual de Informações Sociais, do Ministério do Trabalho e Emprego (Rais/MTE); ii) o Sistema Integrado de Comércio Exterior (Siscomex), da Secretaria de Comércio Exterior do Ministério do Desenvolvimento, Indústria e Comércio Exterior (Secex/MDIC); iii) uma base fornecida pelo MDIC; e iv) informações cedidas pelo BNDES. As unidades de análise são as firmas, identificadas pelo Cadastro Nacional de Pessoa Jurídica (CNPJ) a oito dígitos. O período cobre observações anuais entre 2003 e 2007.

A partir dessa base de dados consolidada, foram realizados dois tipos de análises. Em um primeiro momento, as empresas presentes na base de dados - todas as empresas que, de acordo com a base da Rais, possuem CNPJ ativo - foram classificadas em cinco categorias: i) as que exportam sem fazer uso de nenhum dos três instrumentos de política, denominadas exportadoras independentes; ii) as apoiadas pelo Exim; iii) as apoiadas pelo Proex-financiamento; iv) as apoiadas pelo Proex-equalização; e v) as be-

\footnotetext{
${ }^{1}$ Um dos objetivos da PDP foi o aumento em 10\% do número de empresas exportadoras até 2010 (Brasil/ MDIC, s.d.).

${ }^{2}$ Explicitado como um dos desafios da PDP (Brasil/MDIC, s.d.).
} 
neficiadas pelo regime de drawback ${ }^{3}$. A Tabela 1 mostra o tamanho de cada um destes conjuntos na base de dados.

Tabela 1 - Número de empresas em cada subgrupo (valores absolutos e proporções)

\begin{tabular}{|c|c|c|c|c|c|}
\hline \multicolumn{6}{|c|}{ Números de Empresas } \\
\hline & 2003 & 2004 & 2005 & 2006 & 2007 \\
\hline Total & 1.883 .605 & 1.963 .837 & 2.049 .179 & 2.142 .264 & 2.232 .377 \\
\hline Exportadoras & 28.193 & 29.157 & 29.243 & 29.100 & 28.648 \\
\hline $\begin{array}{l}\text { Exportadoras } \\
\text { independentes }\end{array}$ & 25.852 & 26.479 & 26.321 & 26.215 & 25.572 \\
\hline Exim & 375 & 159 & 171 & 152 & 135 \\
\hline Proex financiamento & 333 & 405 & 448 & 330 & 354 \\
\hline Proex equalização & 42 & 35 & 25 & 29 & 30 \\
\hline Drawback & 2.006 & 2.409 & 2.655 & 2.711 & 2.924 \\
\hline
\end{tabular}

\begin{tabular}{l|c|c|c|c|c}
\multicolumn{7}{c}{ Proporção em Relação às Exportadoras (em Porcentagem) } \\
\hline & $\mathbf{2 0 0 3}$ & $\mathbf{2 0 0 4}$ & $\mathbf{2 0 0 5}$ & $\mathbf{2 0 0 6}$ & $\mathbf{2 0 0 7}$ \\
\hline Total & 66.811 & 67.354 & 70.074 & 73.617 & 77.924 \\
\hline Exportadoras & 1.000 & 1.000 & 1.000 & 1.000 & 1.000 \\
\hline $\begin{array}{l}\text { Exportadoras } \\
\text { independentes }\end{array}$ & 0,917 & 0,908 & 0,900 & 0,901 & 0,893 \\
\hline Exim & 0,013 & 0,005 & 0,006 & 0,005 & 0,005 \\
\hline Proex financiamento & 0,012 & 0,014 & 0,015 & 0,011 & 0,012 \\
\hline Proex equalização & 0,001 & 0,001 & 0,001 & 0,001 & 0,001 \\
\hline Drawback & 0,071 & 0,083 & 0,091 & 0,093 & 0,102 \\
\hline
\end{tabular}

Fonte: Elaboração própria com base em dados de MDIC, BNDES e Rais/MTE.

Após a classificação das empresas, foram extraídas as médias de algumas variáveischave, dentro de cada grupo, em busca de "pistas" a respeito do foco dos programas.

A hipótese que apoia esse exercício pode ser enunciada de maneira simples. Teoricamente, todas as empresas capazes de operar no mercado internacional são clientes potenciais dos instrumentos de promoção de exportação. Por conta disso, é razoável supor que se as políticas fossem concedidas aleatoriamente, ou seja, sem nenhum foco, os perfis das firmas apoiadas e o das exportadoras independentes seriam muito semelhantes. Rigorosamente falando, não seria possível identificar diferença estatística nas médias das principais variáveis entre os grupos.

\footnotetext{
3 A divisão proposta não cria, dentro da base de dados, conjuntos mutuamente excludentes. Uma empresa apoiada pelo BNDES-Exim pode também utilizar o drawback, por exemplo. Desse modo, o número de empresas que aparecem em cada categoria supera o total das exportadoras.
} 
A segunda análise se constituiu em um exercício econométrico com o objetivo de validar as impressões produzidas na análise anterior. Deve-se ressaltar que foram realizados dois grupos de estimações ${ }^{4}$. As variáveis explicativas foram: participação da empresa em cada um dos programas no ano anterior (representadas por dummies); número médio de funcionários no ano anterior (variável em nível) para servir como proxy de tamanho; valor exportado pela firma no ano anterior - considerado zero, caso a firma não tenha exportado; número de trabalhadores qualificados (engenheiros, cientistas e pesquisadores) empregados pela firma; controles para localização geográfica (representados por dummies regionais); e, por fim, uma variável binária que assume o valor 1 (um) quando o setor de atividade é considerado de média-alta ou alta intensidade tecnológica, e zero caso contrário. Dado o reduzido tamanho do programa Proex-equalização, não foi possível realizar qualquer estimação em painel tomando-o como dependente.

\subsection{RESULTADOS}

Os principais resultados obtidos serão resumidamente apresentados neste subitem ${ }^{5}$. A análise das médias das principais variáveis apontou alguns fatos importantes. Em primeiro lugar, apareceram fortes indícios de que o Exim e o Proex-equalização alcançam prioritariamente as grandes empresas exportadoras. A análise sugere, ainda, que o Proex-financiamento é o instrumento mais acessível para firmas menores - ainda que os dados sinalizem que o porte médio dentro desse programa seja maior do que aquele observado entre exportadoras independentes ${ }^{6}$.

Além disso, os dados relativos à escolaridade da força de trabalho e ao contingente empregado de pesquisadores, engenheiros e cientistas apontam para o fato de que as empresas apoiadas costumam empregar uma quantidade maior de profissionais mais qualificados. Os dados sobre a distribuição regional evidenciam que as firmas da região Sul se beneficiam em maior grau dos mecanismos de promoção de exportações

\footnotetext{
${ }^{4}$ Para maiores detalhes e tabelas com coeficientes estimados e estatísticas de teste, ver o anexo de Grimaldi e Carneiro (2010).

${ }^{5}$ As tabelas com todas as estatísticas descritivas elaboradas estão disponíveis em Grimaldi e Carneiro (2010).

${ }_{6}^{6}$ Tal resultado era esperado, na medida em que o Proex-financiamento tem a intenção de privilegiar empresas de pequeno e médio porte. A liberação de recursos para grandes exportadores é submetida a uma série de condicionalidades, e está restrita, basicamente, a operações de venda a outros governos ou instituições governamentais. Para mais informações, ver o art. 10 da Resolução n. 35, de 2007, da Câmara de Comércio Exterior (Camex).
} 
do que as firmas da região Norte, o que pode significar que aquelas encontram maiores facilidades no acesso a tais mecanismos do que estas.

Do ponto de vista do padrão tecnológico, o Exim e, principalmente, o Proexequalização parecem se concentrar em firmas de alta e média-alta intensidade tecnológica ${ }^{7}$. O Proex-financiamento exibe uma tendência de concentração nos nichos de média-baixa e baixa tecnologia.

O exercício econométrico ${ }^{8}$ evidenciou, em primeiro lugar, que, do ponto de vista do foco de ação dos programas, nenhuma das variáveis testadas se mostrou relevante. Ou seja, os resultados indicam que, na prática, nenhuma das três políticas agiu para estimular o perfil de firma exportadora desejado pelos formuladores de políticas. A análise não permitiu a identificação de um foco claro de apoio às empresas de médio e pequeno porte - nem mesmo no caso do Proex-financiamento a variável de porte se mostrou estatisticamente significante -, tampouco de estímulo à exportação de bens com maior sofisticação tecnológica.

O resultado que mais chamou atenção, no entanto, foi o fato de a variável mais relevante para explicar a probabilidade de acesso a um determinado programa ter sido, em todos os casos, a empresa já ter recebido apoio anteriormente, revelando a existência de forte inércia no acesso aos programas. No caso do Exim, por exemplo, a dummy que indica que a firma já utilizava essa linha de financiamento no ano anterior apareceu como significante, com coeficiente positivo e expressivo. Isso se repetiu com o Proexequalização e com o drawback. Era esperado que o fato de a empresa já ser usuária do financiamento surgisse como um fator explicativo relevante. Contudo, essa variável se colocar como a principal, com um coeficiente muito acima dos demais, demonstra uma grande endogenia na utilização dos programas.

A Tabela 2 ilustra essa afirmação. Nela podem ser observadas as probabilidades amostrais de transição. Percebe-se que o número de empresas que não tinham acesso a determinado programa em um certo ano e passaram a utilizá-lo no ano subsequente é muito baixo. Nos casos do Exim e do Proex, o número é próximo à zero. Por sua vez,

\footnotetext{
${ }^{7}$ Para investigar o impacto da sofisticação tecnológica, era preciso enquadrar as diferentes atividades econômicas em uma tipologia que levasse em consideração o esforço dedicado à inovação tecnológica. $\mathrm{O}$ Instituto Brasileiro de Geografia e Estatística (IBGE) propôs, com base em metodologia da Organização Econômica para Cooperação e Desenvolvimento (OCDE), o uso da razão entre gastos com P\&D e receita líquida de vendas como uma boa proxy para mensurar a intensidade da busca pela inovação. A agregação apresentada no presente trabalho foi realizada com base nesta classificação proposta pelo IBGE para a economia brasileira. Para mais informações, ver IBGE (2003).

${ }^{8}$ Detalhes a respeito da metodologia utilizada, além de tabelas completas, com os coeficientes estimados, constam em Grimaldi e Carneiro (2010).
} 
a probabilidade amostral de uma empresa que já utilizava um dos instrumentos continuar utilizando-o nos anos seguintes é bastante elevada ${ }^{9}$.

Tabela 2 - Probabilidades amostrais de transição (em \%)

\begin{tabular}{|c|c|c|}
\hline \multicolumn{3}{|c|}{ BNDES-Exim } \\
\hline & Não utiliza em $t$ & Utiliza em $t$ \\
\hline Não utilizava em $t$-1 & 99,71 & 0,29 \\
\hline Utilizava em $t$-1 & 65,80 & 34,20 \\
\hline \multicolumn{3}{|c|}{ Proex financiamento } \\
\hline & Não utiliza em $t$ & Utiliza em $t$ \\
\hline Não utilizava em $t$-1 & 99,31 & 0,69 \\
\hline Utilizava em $t$-1 & 48,53 & 51,47 \\
\hline \multicolumn{3}{|c|}{ Proex equalização } \\
\hline & Não utiliza em $t$ & Utiliza em $t$ \\
\hline Não utilizava em $t$-1 & 99,98 & 0,02 \\
\hline Utilizava em $t$-1 & 26,19 & 73,81 \\
\hline \multicolumn{3}{|c|}{ Drawback } \\
\hline & Não utiliza em $t$ & Utiliza em $t$ \\
\hline Não utilizava em $t$-1 & 97,42 & 2,58 \\
\hline Utilizava em $t$-1 & 18,13 & 81,87 \\
\hline
\end{tabular}

Fonte: Elaboração própria com base em dados de MDIC, BNDES e Rais/MTE.

Isso significa, por um lado, que existiu uma continuidade dos programas - que permaneceram apoiando o mesmo grupo de firmas por um longo período. Por outro lado, demonstra clara limitação das políticas em expandir o seu alcance. Nos cinco anos analisados, o número de firmas que fez uso dos instrumentos foi bastante restrito e apresentou baixa taxa de transição. Pouquíssimas firmas conseguiram passar do grupo de exportadoras independentes para o grupo das apoiadas. O drawback foi o que apresentou o melhor desempenho nesse quesito. Porém, mesmo nesse caso, a probabilidade amostral de transição é de apenas 2,58\%.

9 O Exim é um caso particular, pois apresenta, mesmo para as empresas que já faziam uso desse instrumento em $t$-1, uma probabilidade razoavelmente baixa de utilização em $t$. Isso se deve a um processo de concentração deste financiamento em um número cada vez menor de firmas. Enquanto os desembolsos do Exim aumentaram de R 12 bilhões para R 14,6 bilhões, entre 2003 e 2007, o número de empresas apoiadas caiu de 375 para 135, no mesmo período. 


\subsection{CONCLUSÕES}

Tomados em conjunto, o Exim, o Proex e o drawback apoiaram pouco mais de $12 \%$ das firmas exportadoras no ano de 2007. O drawback, sozinho, atendia a mais de $10 \%$. Esses índices podem ser considerados tímidos para um país que tem a intenção declarada de aumentar a sua base exportadora.

Os resultados obtidos indicam que, no concernente ao perfil desejado para as exportações, o Exim, o Proex e o drawback foram pouco eficazes em alcançar os principais objetivos. Nem o padrão de sofisticação tecnológica, nem o porte das empresas surgiram como fatores relevantes no acesso aos programas, o que indica necessidade de redesenho das políticas para que elas atinjam, de maneira mais satisfatória, o seu foco.

Contudo, a conclusão mais forte do estudo é que existiu, no período analisado (2003-2007), uma forte inércia na dinâmica dos instrumentos. Isso não é necessariamente ruim, pois demonstra que os mecanismos são muito bem avaliados pelas empresas que os utilizam. Entretanto, a almejada expansão do alcance dos programas, que provavelmente implicará em um crescimento da base exportadora, exige uma ação mais efetiva por parte do governo. Tal mudança pode incluir: melhor divulgação das linhas de financiamento; um redesenho das políticas, reduzindo ou flexibilizando as exigências para o acesso; ou ainda a criação de novos instrumentos, com mais atratividade e, consequentemente, com maior poder de viabilizar a entrada de novas empresas brasileiras no mercado internacional.

\section{LEI DO BEM: IMPACTOS NAS ATIVIDADES DE P\&D NO BRASIL}

\subsection{INTRODUÇÃO}

Incentivo fiscal é um tradicional mecanismo de apoio à inovação adotado em diversos países. Estima-se que esse tipo de incentivo corresponda a 6,9\% dos investimentos privados em atividades de $\mathrm{P} \& \mathrm{D}$ realizados nos países da Organização para a Cooperação e Desenvolvimento Econômico (OCDE) (Corder, 2006). Em 2010, 18 países da OCDE concederam algum tipo de benefício fiscal a essas atividades, enquanto em 1996 apenas 12 o fizeram. Tais incentivos incluem dedução imediata dos gastos correntes com P\&D, crédito fiscal ou dedução de lucros tributáveis, alguns beneficiando aumentos nos investimentos em $\mathrm{P} \& \mathrm{D}$ e outros se baseando no nível de investimentos no ano corrente (Moreira et al., 2007). Esse instrumento não tem sido exclusivo de nações avançadas: países em desenvolvimento, como China e Índia, adotam-no para estimular o desenvolvimento tecnológico do setor privado. 
Incentivos fiscais permitem que a alocação de recursos em atividades tecnológicas, como P\&D, seja definida pelo mercado, segundo projetos de interesse do setor produtivo, mesmo na presença de tratamento preferencial a atividades como pesquisa básica, ou a grupos específicos como pequenas empresas. Em geral, envolvem baixos custos de administração - inferiores aos incentivos financeiros -, mas podem se tornar onerosos pela magnitude da renúncia fiscal envolvida. Se, por um lado, a seleção de projetos pelo mercado é vista como um aspecto positivo, por outro, o instrumento pode ser criticado por não direcionar os investimentos públicos para inovações em áreas definidas como prioritárias pelo governo.

Em relação ao estímulo a atividades privadas em $\mathrm{P} \& \mathrm{D}$, os incentivos fiscais são considerados um instrumento complementar a outros fatores, como o crescimento econômico, a infraestrutura científica e tecnológica local, e a disponibilidade de recursos humanos qualificados (UNCTAD, 2005).

A literatura sobre incentivos fiscais à $\mathrm{P} \& \mathrm{D}$ se dedica a investigar a existência de efeitos crowding in, ou efeito adicionalidade, e crowding out, ou efeito substituição. No primeiro caso, os incentivos seriam capazes de estimular as empresas a investirem em P\&D um montante superior ao que seria alocado na ausência do instrumento. No segundo, as empresas investiriam em P\&D o mesmo montante que o fariam na ausência do instrumento, e os incentivos públicos apenas substituiriam recursos privados (Avellar, 2008), caso no qual os incentivos fiscais funcionam como compensação ao empresário inovador, e não como mecanismo necessário à realização do investimento.

\subsection{INCENTIVOS FISCAIS À INOVAÇÃO NO BRASIL: A LEI DO BEM}

No Brasil, o Capítulo III da Lei no 11.196/2005, conhecida como Lei do Bem, é atualmente o mais abrangente incentivo fiscal de estímulo à inovação. Ele dá cumprimento à determinação da Lei $n^{\circ} 10.973 / 2004$, a qual estabeleceu que a União deve fomentar a inovação na empresa mediante a concessão de incentivos fiscais ${ }^{10}$.

Até a introdução da Lei do Bem, a política de incentivos fiscais à inovação seguia as determinações da Lei $n^{\circ} 8.661 / 1993$, que representou a retomada do mecanismo enquanto instrumento da política tecnológica no Brasil (Guimarães, 2006). A obtenção de incentivos fiscais estava condicionada à execução de programas de desenvolvimento

\footnotetext{
${ }^{10}$ Além da Lei do Bem, existem outros instrumentos fiscais de apoio à inovação tecnológica no Brasil, como a Lei de Informática (Lei n 8.248/1991). A partir da Medida Provisória n 428/2008, convertida na Lei $n^{\circ} 11.774 / 2008$, os beneficiários da Lei de Informática passaram a ter direito de usufruir os benefícios da Lei do Bem.
} 
tecnológico industrial (PDTI) e agropecuário (PDTA) pelas empresas. Os PDTI e os PDTA deveriam ser aprovados pelo Ministério da Ciência e Tecnologia (MCT) ou por órgãos e entidades federais e estaduais de fomento ou pesquisa tecnológica credenciados pelo MCT para o exercício dessa atribuição. A complexidade dos formulários utilizados nesse processo foi considerada um dos principais obstáculos à utilização do instrumento (Matesco e Tafner, 1996).

Em 1997, os incentivos da Lei no 8.661/1993 sofreram alterações, relacionadas essencialmente com a redução significativa de porcentagens envolvidas (Lei no 9.532/1997). Posteriormente, as modificações incluíram a autorização da concessão de subvenção econômica a empresas engajadas nos referidos programas (Lei no 10.332/2001) e, paralelamente, a ampliação dos incentivos até então existentes (Lei n 10.637/2002)

Em 2005, o Capítulo III da Lei do Bem consolidou os dois textos legais que definiam a política de incentivos às atividades de $\mathrm{P} \& \mathrm{D}$ e à inovação (Lei no 8.661/1993 e Lei $\left.\mathrm{n}^{\circ} 10.637 / 2002\right)$, revogando os mecanismos anteriormente vigentes. Com sua introdução, o procedimento burocrático foi simplificado, ao não se exigir a pré-aprovação de projetos ou participação em editais licitatórios. De acordo com a Lei do Bem e com o Decreto no 5.798/2006, que regulamentou a utilização dos incentivos fiscais, as empresas devem enviar ao MCT, por meio eletrônico, as informações anuais sobre os seus programas de P\&D. O prazo para o repasse das informações é 31 de julho do ano subsequente a cada exercício fiscal.

As despesas de custeio com P\&D são classificadas como "custos operacionais" pela legislação do Imposto de Renda Pessoa Jurídica (IRPJ) sendo, por isso, excluídas da base de cálculo da Contribuição Social sobre o Lucro Líquido (CSLL) e do IRPJ de qualquer empresa. A Lei do Bem (Capítulo III, arts. 17 a 26) se traduz, portanto, em um ganho real com despesas realizadas em $P \& D$, que pode ser resumido conforme a seguir:

- Exclusão, do lucro líquido e da base de cálculo da CSLL, do valor correspondente a: - Até $60 \%$ da soma dos dispêndios realizados com P\&D no período, classificados como despesas operacionais pela legislação do IRPJ;

- Até $20 \%$, no caso de incremento do número de pesquisadores dedicados à $\mathrm{P} \& \mathrm{D}$ contratados no ano de referência; e

- Até $20 \%$, no caso de patente concedida ou cultivar registrado.

- Redução de 50\% do Imposto sobre Produtos Industrializados (IPI) incidente sobre equipamentos, máquinas, aparelhos e instrumentos importados para realização de P\&D.

- Depreciação e amortização acelerada de equipamentos e bens intangíveis empregados em P\&D.

- Redução a zero da alíquota do IRPJ nas remessas efetuadas para o exterior destinadas ao registro e manutenção de marcas, patentes e cultivares. 


\subsection{LEI DO BEM: AVALIAÇÃO POR TAMANHO, ORIGEM DE CAPITAL E SETOR}

A análise a seguir avalia as empresas que acessaram a Lei do Bem, em 2008, comparando-as com o resultado da Pesquisa Industrial de Inovação Tecnológica (PINTEC), do IBGE, de 2005. Os indicadores foram classificados por tamanho, setor e origem de capital, uma vez que são categorias importantes na análise de investimentos em P\&D.

O número de empresas beneficiadas pelo instrumento vem apresentando crescimento significativo ao longo dos anos. Em 2006, foram 130 e, em 2007, 299 empresas. Em 2008, 441 empresas foram beneficiadas pelos incentivos fiscais previstos no Capítulo III da Lei do Bem. Entre estas, 63,5\% foram classificadas como nacionais e 36,5\% como multinacionais ${ }^{11}$. Empresas de grande porte (acima de 500 empregados) dominam a amostra, representando 59,0\% do total de empresas beneficiadas e 93,4\% dos gastos de custeio em P\&D (Tabela 3 ).

Tabela 3 - Empresas beneficiadas pelo Capítulo III da Lei do Bem: número de empregados e gastos de custeio em P\&D (2008)

\begin{tabular}{c|c|c|c}
\hline \multirow{2}{*}{ Número de Empregados } & Nacional & Multinacional & Total \\
\cline { 2 - 4 } & $15,9 \%$ & $7,5 \%$ & $12,7 \%$ \\
\hline$>100$ & $31,1 \%$ & $23,8 \%$ & $28,3 \%$ \\
\hline$>100 \mathrm{a} \leq 500$ & $18,9 \%$ & $20,6 \%$ & $19,6 \%$ \\
\hline$>1.000$ & $34,1 \%$ & $48,1 \%$ & $39,4 \%$ \\
\hline Total $\leq 1.000$ & $100,0 \%$ & $100,0 \%$ & $100,0 \%$ \\
\hline \multirow{2}{*}{ Número de Empregados } & & Gastos de Custeio em P\&D & Total \\
\hline \multirow{2}{*}{$\leq 100$} & Nacional & Multinacional & $2,1 \%$ \\
\hline$>100$ a $\leq 500$ & $4,3 \%$ & $0,4 \%$ & $4,5 \%$ \\
\hline$>500$ a $\leq 1.000$ & $6,3 \%$ & $3,2 \%$ & $6,9 \%$ \\
\hline$>1.000$ & $7,9 \%$ & $6,1 \%$ & $88,6 \%$ \\
\hline Total & $81,4 \%$ & $90,3 \%$ & $100,0 \%$ \\
\hline
\end{tabular}

Nota: Excluiu-se número equivalente a 3,9\% das empresas, por não terem sido encontradas na MTE/Rais. Fonte: Elaboração própria com base em dados de Brasil/MCT (2009), MTE/Rais e Banco Central do Brasil.

A própria definição da lei atrai esse perfil empresarial, tendo em vista que, para usufruir dos benefícios, a empresa precisa não somente obter lucro no ano-base, mas também é mandatório que a declaração do Imposto de Renda de Pessoa Jurídica (IRPJ)

11 As empresas brasileiras foram classificadas em nacionais e multinacionais de acordo com o Censo de Capitais Estrangeiros do Banco Central do Brasil, ano 2000. Empresas multinacionais são aquelas em que o capital estrangeiro representa $50 \%$ ou mais no capital votante da firma. 
seja feita sob o regime de lucro real. Uma vez que empresas de pequeno porte podem e tendem a preferir fazê-lo - declarar o IRPJ pelo regime de lucro presumido ${ }^{12}$, essas se veem impossibilitadas de acessar os recursos da Lei do Bem.

Vale lembrar que, embora apenas $12 \%$ das empresas que realizaram atividades de P\&D no país sejam de grande porte, elas são responsáveis por $75 \%$ do montante investido no país (PINTEC/IBGE, 2005).

As empresas beneficiadas também apresentaram alta inserção no comércio internacional - mais de $70 \%$ do total de empresas beneficiadas eram exportadoras e/ou importadoras (Tabela 4).

Tabela 4 - Empresas beneficiadas pelo Capítulo III da Lei do Bem: comércio exterior (2008)

\begin{tabular}{l|c|c|c}
\hline \multicolumn{1}{c|}{ Lei do Bem (2008) } & Nacional & Multinacional & Total \\
\hline Empresas exportadoras/Total & $71,8 \%$ & $90,7 \%$ & $78,7 \%$ \\
\hline Empresas importadoras/Total & $84,6 \%$ & $97,5 \%$ & $89,3 \%$ \\
\hline
\end{tabular}

Fonte: Elaboração própria com base em dados de Brasil/MCT (2009), MDIC e MTE.

Analisando-se as empresas beneficiadas em 2008 pela Lei do Bem por setor da indústria de transformação, é possível observar que aproximadamente $67,1 \%$ dos gastos de custeio em P\&D de empresas multinacionais que acessaram a Lei do Bem estão concentrados na indústria automobilística (veículos e peças). No caso de empresas nacionais, os benefícios se concentraram nos setores de petróleo $(50,1 \%)$ e outros equipamentos de transporte, incluindo aeronaves (19,1\%). Em suma, 70,3\% dos gastos totais de custeio em P\&D das empresas da indústria de transformação que acessaram a Lei do Bem foram direcionados às indústrias petrolífera, automobilística e aeronáutica, todas elas já largamente consolidadas na estrutura produtiva brasileira (Tabela 5) ${ }^{13}$.

12 Podem optar pelo lucro presumido pessoas jurídicas cuja receita bruta total seja igual ou inferior a $\mathrm{R} \$ 48$ milhões anuais, no ano-calendário anterior, ou a R\$ 4 milhões, multiplicado pelo número de meses em atividade no ano-calendário anterior. Sobre o assunto, ver: <www.receita.fazenda.gov.br>.

${ }_{13}$ A análise considerou somente setores da indústria de transformação para viabilizar a comparação com as estatísticas da PINTEC. Os gastos de custeio em P\&D da indústria de transformação representaram, em 2008 , aproximadamente $79 \%$ do total despendido pelas empresas que tiveram acesso aos recursos da Lei do Bem, analisados, alcançando R\$ 6,6 bilhões. 
Tabela 5 - Participação setorial nos gastos de custeio em P\&D (2008)

Lei do Bem 2008

Indústria de Transformação

\begin{tabular}{|c|c|c|c|}
\hline Setores & Nacional & Multinacional & Total \\
\hline Alimentos e bebidas & $2,09 \%$ & $2,76 \%$ & $2,45 \%$ \\
\hline Fumos & $0,04 \%$ & $1,75 \%$ & $0,96 \%$ \\
\hline Têxteis & $0,40 \%$ & - & $0,18 \%$ \\
\hline Confecções & $0,01 \%$ & - & $0,00 \%$ \\
\hline Couro e calçados & $3,24 \%$ & - & $1,49 \%$ \\
\hline Produtos de madeira & $0,33 \%$ & - & $0,15 \%$ \\
\hline Celulose e papel & $0,64 \%$ & $0,39 \%$ & $0,50 \%$ \\
\hline Editoração & $0,02 \%$ & $0,01 \%$ & $0,02 \%$ \\
\hline Petróleo e álcool & $50,05 \%$ & - & $23,00 \%$ \\
\hline Produtos químicos & $6,75 \%$ & $7,12 \%$ & $6,95 \%$ \\
\hline Produtos de borracha e plástico & $1,48 \%$ & $2,19 \%$ & $1,86 \%$ \\
\hline Produtos minerais não metálicos & $0,22 \%$ & $0,06 \%$ & $0,14 \%$ \\
\hline Metalurgia básica & $4,83 \%$ & $3,02 \%$ & $3,85 \%$ \\
\hline Produtos de metal & $0,68 \%$ & $0,28 \%$ & $0,47 \%$ \\
\hline Máquina e equipamentos & $2,89 \%$ & $8,08 \%$ & $5,70 \%$ \\
\hline Escritório e informática & $0,23 \%$ & - & $0,11 \%$ \\
\hline Produtos elétricos & $0,85 \%$ & $1,74 \%$ & $1,33 \%$ \\
\hline Produtos eletrônicos & $1,73 \%$ & $3,32 \%$ & 2,59 \\
\hline Instrumentalização & $0,56 \%$ & $0,65 \%$ & $0,61 \%$ \\
\hline Veículos & $3,41 \%$ & $67,07 \%$ & $37,82 \%$ \\
\hline Outros equipamentos de transporte & $19,11 \%$ & $1,24 \%$ & $9,45 \%$ \\
\hline Móveis e indústrias diversas & $0,44 \%$ & $0,32 \%$ & $0,38 \%$ \\
\hline
\end{tabular}

Nota: Excluíram-se duas empresas beneficiadas, que representam 0,37\% dos dispêndios de custeio em P\&D da indústria de transformação. Fonte: Elaboração própria com base em dados de Brasil/MCT (2009).

Se comparadas essas informações com as divulgadas pela PINTEC, nota-se que, em 2005, o setor de petróleo respondeu por 34,7\% dos dispêndios em P\&D de empresas nacionais de grande porte no Brasil, enquanto o setor de outros equipamentos de transporte representou 26,9\%. Entre as multinacionais, o setor automobilístico respondeu por $53,8 \%$ (Tabela 6 ). 
Tabela 6 - Gasto em atividades internas de P\&D: participação setorial por origem de capital segundo a Pintec 2005

\begin{tabular}{|c|c|c|c|}
\hline \multicolumn{4}{|c|}{ Empresas Brasileiras de Grande Porte } \\
\hline Setores/Origem de capital & Nacionais & Multinacionais & Total \\
\hline Alimentos e bebidas & $3,0 \%$ & $3,2 \%$ & $3,1 \%$ \\
\hline Fumos & $\mathrm{X}^{* *}$ & $0,7 \%$ & $0,3 \%$ \\
\hline Têxteis & $1,3 \%$ & $0,1 \%$ & $0,7 \%$ \\
\hline Confecções & $0,4 \%$ & $\mathrm{X}^{* *}$ & $0,2 \%$ \\
\hline Couro e calçados & $2,1 \%$ & $\mathrm{X}^{* *}$ & $1,1 \%$ \\
\hline Produtos de madeira & $0,6 \%$ & $0,0 \%$ & $0,3 \%$ \\
\hline Celulose e papel & $2,1 \%$ & $0,9 \%$ & $1,6 \%$ \\
\hline Petróleo e álcool & $34,7 \%$ & $\mathrm{X}^{* *}$ & $18,5 \%$ \\
\hline Produtos químicos & $6,5 \%$ & $9,6 \%$ & $8,0 \%$ \\
\hline Produtos farmacêuticos & $2,4 \%$ & $3,7 \%$ & $3,0 \%$ \\
\hline Artigos de borracha e plástico & $1,1 \%$ & $3,8 \%$ & $2,3 \%$ \\
\hline Produtos minerais não metálicos & 1,6 & $1,2 \%$ & $1,4 \%$ \\
\hline Metalurgia básica & $3,4 \%$ & $2,8 \%$ & $3,1 \%$ \\
\hline Produtos de metal & $0,7 \%$ & $0,3 \%$ & $0,5 \%$ \\
\hline Máquinas e equipamentos & $2,8 \%$ & $4,9 \%$ & $3,8 \%$ \\
\hline Escritório e informática & $0,7 \%$ & $2,0 \%$ & $1,3 \%$ \\
\hline Produtos elétricos & $3,3 \%$ & $9,8 \%$ & $6,3 \%$ \\
\hline Produtos eletrônicos/comunicação & $3,3 \%$ & $5,9 \%$ & $4,5 \%$ \\
\hline Instrumentação & $0,5 \%$ & $0,1 \%$ & $0,3 \%$ \\
\hline Indústria automobilística & $3,7 \%$ & $53,8 \%$ & $27,1 \%$ \\
\hline Outros equipamentos de transporte & $26,9 \%$ & $0,8 \%$ & $14,7 \%$ \\
\hline Móveis e indústrias diversas & $1,3 \%$ & $0,3 \%$ & $0,8 \%$ \\
\hline
\end{tabular}

Nota: (') Valor sob sigilo. Não se incluíram valores referentes a setores que gozam de sigilo.

Fonte: Elaboração própria com base em dados de PINTEC/IBGE (2005).

Essas porcentagens revelam significativa correlação setorial entre os gastos em P\&D de grandes empresas disponibilizados pela PINTEC e os dispêndios de custeio em P\&D de empresas que acessaram os mecanismos da Lei do Bem, em 2008. A correlação, representada no Gráfico 1, alcançou 95,8\%. Em outras palavras, a concessão dos benefícios previstos na Lei do Bem reproduz, quase que integralmente, a distribuição setorial dos esforços em $\mathrm{P} \& \mathrm{D}$ que o Brasil já vinha realizando, indicando que o instrumento ainda foi incapaz de diversificar a estrutura setorial do desenvolvimento tecnológico nacional. 


\section{Gráfico 1 - Participação setorial dos gastos em P\&D de grandes empresas segundo a PINTEC} (2005) e no âmbito da Lei do Bem (2008)

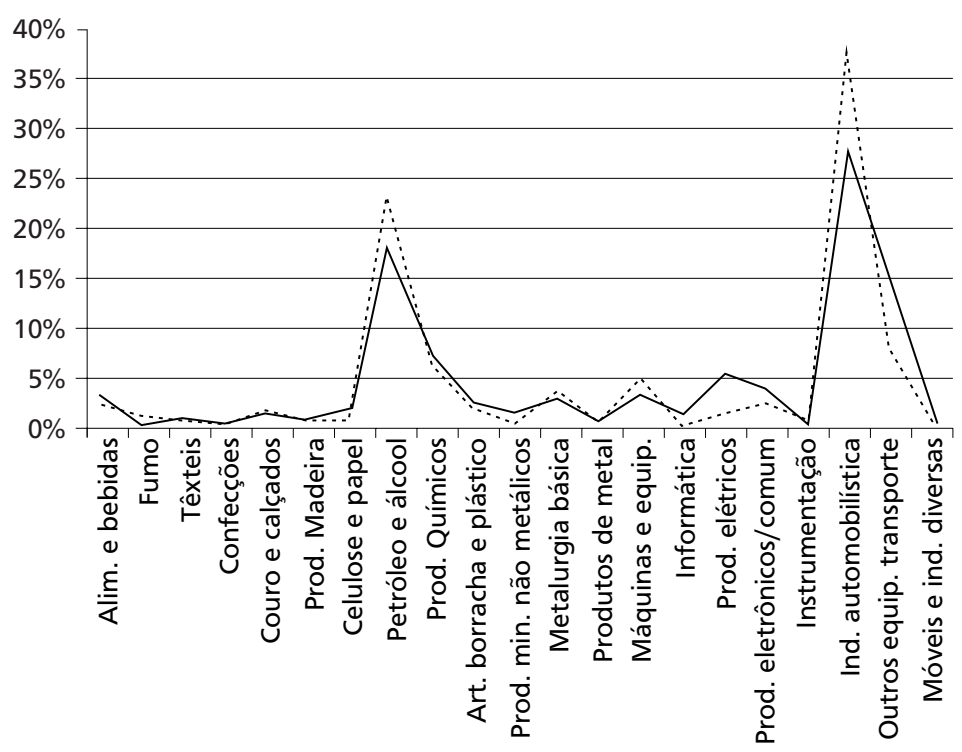

Pintec

Lei do bem 2008

Fonte: Elaboração própria com base em dados de PINTEC/IBGE (2005) e Brasil/MCT (2009).

\subsection{CONCLUSÕES}

Os resultados da Lei do Bem são relevantes para investigar sua capacidade de estimular investimentos privados em P\&D. A análise preliminar sugere que esse instrumento ainda não foi capaz de estimular a diversificação setorial desses investimentos no Brasil, dado que seus benefícios são majoritariamente capturados por setores que já desenvolviam essa atividade. Nesta avaliação, é importante considerar a interação da Lei do Bem com outros instrumentos de apoio à inovação, que podem atuar de forma complementar para contribuir com o desenvolvimento tecnológico do setor produtivo nacional.

Com base na análise realizada, é possível levantar algumas questões: estimular a diversificação setorial pode ser considerado um dos objetivos da Lei do Bem? Ou seu intuito é, essencialmente, promover o efeito adicionalidade, incentivando investimentos privados em $P \& D$, independentemente do porte ou setor envolvido? Qual é a capacidade da Lei do Bem para estimular empresas que ainda não realizam P\&D no país? Por fim, os incentivos fiscais à inovação provenientes da Lei do Bem - que, segundo relatório do MCT, alcançaram R \$ 1,5 bilhão em 2008 - poderiam ser utilizados de forma mais eficaz na promoção e disseminação de atividades tecnológicas nos setores produtivos do país? 
Ainda é cedo para se estabelecer um diagnóstico conclusivo em relação a esse instrumento e inferir acerca de seu potencial futuro de estímulo à inovação. Sua consolidação no cenário nacional ainda pode vir a se revelar capaz de incentivar um maior número de empresas, em setores diversos, a incluírem atividades de $\mathrm{P} \& \mathrm{D}$ entre suas prioridades em médio prazo. Também pode se revelar importante para diferenciar o Brasil de outros países, elevando sua capacidade de competir por recursos estrangeiros.

\section{O FUNDO SETORIAL DE TECNOLOGIA DA INFORMAÇÃO (CT-INFO)}

\subsection{INTRODUÇÃO}

A partir do processo de privatizações de diversos setores da economia brasileira - com destaque para os setores de petróleo, telecomunicações e energia elétrica -, o governo federal entendeu ser necessário aumentar os recursos destinados às atividades de ciência e tecnologia (C\&T), bem como garantir um fluxo constante de tais recursos. Com esse objetivo, foi implantado em 1999 o fundo setorial de petróleo e gás natural, o CT-Petro. Após a experiência do CT-Petro, que serviu como piloto, foram criados, entre os anos de 2000 e 2001, outros fundos setoriais, a saber: energia elétrica; recursos hídricos; transportes terrestres; mineração; espacial; tecnologia da informação; infraestrutura; saúde; agronegócio; verde-amarelo; biotecnologia; aeronáutico; telecomunicações; Amazônia; aquaviário; e construção naval (Brasil/MCT, s.d.).

Esse conjunto de fundos setoriais visa apoiar o desenvolvimento científico e tecnológico, e garantir a ampliação e a estabilidade do financiamento para a área de C\&T. Eles visam promover o desenvolvimento e a consolidação de parcerias entre universidades e centros de $\mathrm{P} \& \mathrm{D}$, públicos ou privados, além de procurarem induzir o aumento dos investimentos do setor empresarial em C\&T, impulsionando o desenvolvimento tecnológico dos setores considerados e promovendo maior sinergia entre o conjunto de agentes. Buscam, ainda, o incentivo à geração de conhecimento e inovações que contribuam para a solução dos grandes problemas nacionais. $\mathrm{O}$ crédito é concedido diretamente a uma ICT e, em muitos casos, envolve uma parceria deste com empresas participantes do projeto.

\subsection{DESENHO DO ESTUDO}

O CT-Info tem como objetivo "Fomentar projetos estratégicos de pesquisa e desenvolvimento em tecnologia da informação para as empresas brasileiras do setor de informática" (Brasil/MCT, s.d.). Assim, o estudo buscou compreender a dinâmica 
do instrumento em sua operacionalização e difusão no contexto dessas empresas. Para tanto, estabeleceram-se as questões de trabalho a seguir:

1. Qual é o perfil das empresas que obtiveram recursos concedidos pelo CT-Info?

2. Como se desenvolveu a dinâmica de utilização desses recursos?

3. Qual é a motivação para que empresas recorram ou não ao instrumento?

Para as duas primeiras questões e parte da terceira, o objeto desse estudo foram as empresas que se beneficiaram dos recursos do CT-Info; para a parte da terceira questão relativa à não utilização do instrumento, os alvos foram aquelas empresas que, desde a criação do programa, dele não fizeram uso.

Partindo dessas questões e da distinção de seus respectivos alvos, o trabalho foi subdividido em duas pesquisas distintas: uma pesquisa de campo com caráter qualitativo, tendo com objeto o universo de empresas que compõem o primeiro grupo; e uma survey direcionada a uma amostra do conjunto de empresas que desenvolvem software no país e que não fazem parte do primeiro grupo, ou seja, que não tomaram parte em projetos financiados com recursos do CT-Info.

Para a determinação do universo de empresas a ser considerado para o primeiro grupo, foram utilizados os dados fornecidos pelo MCT. Após um levantamento na base de dados dos contratos, foram identificadas 117 empresas beneficiadas entre os 524 projetos financiados pelo CT-Info desde 2002 até 2009. Posteriormente, buscou-se estabelecer contato por correio eletrônico com os coordenadores dos projetos realizados em ICT e, por seu intermédio, obter os contatos dos representantes das firmas envolvidas nos projetos. Dos 97 coordenadores de projetos com participação de empresas, 55 atenderam à solicitação (58,5\% do total), fornecendo os dados relativos a 60 empresas (51,3\% das empresas), participantes de 66 projetos. Saliente-se que alguns projetos envolvem mais de uma empresa, ao passo que algumas empresas estão envolvidas em mais de um projeto. Uma vez que esse conjunto de 60 empresas ultrapassa a metade do universo de 117 firmas beneficiadas, esse número foi considerado como adequadamente representativo e, portanto, definido como a amostra da pesquisa.

A segunda amostra, destinada à pesquisa com empresas que não tomaram parte nos projetos financiados pelo CT-Info, foi construída por intermédio de listas de e-mails obtidas em entidades de classe do setor de desenvolvimento de software. Trata-se de empresas que têm o desenvolvimento de software como atividade significativa de seu processo produtivo, seja como produto final, seja como "software embarcado". Cotejadas com os dados do CT-Info, foram excluídas das listas as empresas que estavam relacionadas entre as 117 anteriores. Obteve-se, assim, uma relação na qual constavam 701 companhias. 
Para o primeiro conjunto de empresas, e tendo em vista as duas questões propostas, planejou-se a realização de entrevistas com os responsáveis pelos projetos. Para o segundo conjunto de empresas, foi realizada uma survey enviada por correio eletrônico para os seus responsáveis, na qual foram enumeradas as possíveis motivações para que uma empresa não houvesse sido agraciada com os subsídios do CT-Info. Essas motivações foram ordenadas em uma questão "fechada", de múltipla escolha, com resposta única (opções mutuamente excludentes). O questionário contava, ainda, com uma questão aberta, a qual permitia comentários.

\subsection{RESULTADOS}

\subsubsection{ENTREVISTAS}

No grupo das 60 empresas que obtiveram o crédito, responsáveis por 66 projetos, foi possível entrevistar um total de 47 empresas, responsáveis por 53 contratos de crédito no CT-Info.

Entre os diversos resultados observados, um ponto de interesse é o baixo índice de mortalidade das empresas: duas empresas entre as 20 iniciantes (até quatro anos de vida), correspondendo a 10,0\% do total. Esse valor contrasta com a média nacional de mortalidade nos dois primeiros anos de vida, que, segundo o Serviço Brasileiro de Apoio às Micro e Pequenas Empresas (Sebrae, 2007), variou entre 49,4\% em 2002 e 22,0\% em 2005.

Esse fenômeno pode se relacionar ao instrumento de estímulo de dois modos: como consequência; ou como causa. Como consequência, pode-se supor que a baixa taxa de mortalidade é decorrência dos benefícios produzidos pelo instrumento nos negócios da firma, contribuindo com sua consolidação. Como causa, em função de uma seletividade na busca do financiamento, ou seja, uma tendência de que as firmas mais bem estruturadas - isto é, com maiores chances de sobrevivência - recorram ao instrumento. Em função do que foi observado nas entrevistas, deve-se admitir que ambas as situações estejam presentes. Há, de fato, uma predominância de companhias mais bem estruturadas nas que fazem uso do CT-Info, uma vez que a maioria é oriunda de incubadoras e, conforme demonstrado por Greco et al. (2009), esse fator está fortemente associado a uma redução na "mortalidade infantil" das empresas. Contudo, isso não explica isoladamente o resultado, uma vez que, segundo aquele trabalho, o índice se situa em torno dos $20 \%$ para as incubadas. Tendo como base os depoimentos dos entrevistados, é possível admitir que o baixo índice verificado seja também resultado dos impactos positivos do financiamento nos negócios das empresas que dele fizeram uso.

Observou-se, também, que as firmas que tiveram sua origem (ou consolidação) dentro de incubadoras constituem o grupo majoritário: 32 firmas $(68,1 \%)$. Se se levar em conta que, das 15 empresas que não tiveram essa origem, 12 são grandes empresas, e 
que dez tinham idade acima de 20 anos quando recorreram ao crédito, é lícito concluir que, dentro do grupo de pequenas e médias empresas (PME), a vinculação a incubadoras é quase absoluta. Esse fenômeno admite duas explicações. A primeira delas é que o instrumento não está adequadamente divulgado no contexto geral da indústria, ficando restrito ao universo de organizações que, de algum modo, estão vinculadas às redes de institutos de pesquisas. A segunda explicação, que reforça a primeira, é a de que a liturgia de obtenção do crédito incorpora um conjunto de procedimentos e conhecimentos tácitos não acessíveis às PME que não contam com alguma forma de apoio de organizações que dominem esse ritual.

Ademais, próximo de 3/4 dos contratos firmados por empresas surgidas em incubadoras tiveram início quando a firma ainda se encontrava incubada. Esse fato reforça o vínculo de dependência entre as que têm acesso ao mecanismo de fomento e o que pode ser chamado de complexo acadêmico-universitário (CAU): universidades; institutos e centros de pesquisas; organizações voltadas para o desenvolvimento tecnológico; incubadoras; parques tecnológicos; fundações universitárias etc.

Entre as 15 firmas não originárias de incubadoras, encontram-se três multinacionais com uma longa tradição de $\mathrm{P} \& \mathrm{D}$ e, consequentemente, de relacionamento com o CAU; além dessas, existem duas grandes companhias nacionais com perfil semelhante. A elas somam-se quatro empresas formadas por professores universitários, e mais três constituídas a partir da associação de alunos de graduação e pós-graduação que decidiram explorar comercialmente seus projetos de pesquisa acadêmica. Existe, ainda, outra empresa cujo produto básico desenvolvido lhe foi transferido por uma universidade com a qual tem diversas parcerias. Finalmente, uma última empresa caracteriza-se como um spin-off de uma instituição científica que atua em uma área de tecnologia de fronteira. Assim, chama atenção que apenas uma entre as 47 organizações entrevistadas não possua um estreito vínculo com o $\mathrm{CAU}$, o que indica claramente a captura do instrumento por parte deste complexo.

Tendo-se em conta o número reduzido de projetos financiados pelo CT-Info que contemplaram a participação direta do setor produtivo ${ }^{14}$, reforça-se a suposição de que existe uma difusão muito baixa do instrumento junto ao universo de empresas que não se vinculam ao CAU. Quase metade das firmas ( $46,8 \%$ do total) já havia recorrido a outros instrumentos de crédito voltados para estas atividades antes de fazerem uso do CT-Info. Aproximadamente $30 \%$ tiveram no CT-Info sua primeira experiência com instrumentos desta natureza, mas, após este, continuaram utilizando-se de financiamento incentivado

\footnotetext{
${ }^{14}$ Do total de 524 projetos financiados pelo fundo, empresas tomaram parte em apenas 117 deles $(22,3 \%)$.
} 
para suas atividades de $\mathrm{P} \& \mathrm{D}$. Apenas cerca de $20 \%$ tiveram o projeto financiado pelo CTInfo como a única situação em que fizeram uso de recursos desta natureza.

Praticamente todos os instrumentos de fomento à CT\&I existentes no país foram citados pelas firmas que deles se utilizaram antes ou depois do CT-Info. Destacam-se a Lei de Informática, outros fundos setoriais, créditos de fundações estaduais de amparo à pesquisa, créditos do BNDES, bolsas do Programa de Capacitação de Recursos Humanos para Atividades Estratégicas (RHAE), Venture Fórum, programa Juro Zero, entre outros.

A despeito de a iniciativa dos projetos financiados ter sido majoritariamente originária das empresas, 14 deles foram idealizados pelas instituições de pesquisa (IP). São situações em que havia um interesse específico da IP no escopo do edital e, assim, esta procurou a empresa oferecendo a oportunidade de beneficiar-se do instrumento. Em geral, as firmas que foram procuradas nesses casos possuíam algum tipo de vínculo anterior com o IP em questão. Três situações que se apresentam como uma flagrante distorção dos princípios e objetivos do CT-Info puderam ser identificadas. Nelas, a empresa atuou apenas como fachada no projeto que, na verdade, financiou atividades de pesquisa puramente acadêmicas, tendo a empresa apenas emprestado seu nome para atender às exigências do edital. Há, ainda, outros dois registros nos quais a situação foi inversa. A IP atuou como fachada para um projeto que atendia a interesses exclusivos da empresa e cujo desenvolvimento ficou inteiramente a cargo desta, não tendo o IP nenhuma participação efetiva em seu desenvolvimento.

Na identificação dos problemas vivenciados pelas organizações no transcurso do projeto, um dos pontos mais frequentes e veementemente destacados pelos entrevistados diz respeito aos seus aspectos formais. São questões que concernem à burocracia na submissão, acompanhamento e prestação de contas dos projetos e ao formalismo envolvido nessas tarefas. Os entrevistados deram ênfase à falta de flexibilidade na gestão dos recursos - que compromete a dinâmica exigida pelo contexto empresarial, dificulta contratações de recursos humanos necessários aos projetos e não se adéqua às incertezas das atividades de pesquisa. Impactos semelhantes advêm do "excesso irracional de burocracia" - reiterado pelos entrevistados - que, além disso, posto que dificulte a prestação de contas, acaba por contribuir para os atrasos nas liberações das demais parcelas. A conjugação dessas duas características exige, por parte das empresas, a realização de um significativo esforço adicional em atividades burocrático-administrativas que fogem aos objetivos dos projetos.

Quanto à sistemática de acompanhamento, o que se destacou foi que seu escopo exclusiva e excessivamente "formal e burocrático" contribui, por um lado, com as dificuldades enumeradas e, por outro, não resulta em uma avaliação efetiva do desenvolvimento dos projetos nem colabora no sentido de que seus processos sejam mais eficazes. Na realidade, na visão dos entrevistados, não há um acompanhamento de fato, mas sim uma mera "fiscalização". 
Os diversos depoimentos coligidos por meio das entrevistas possibilitam algumas ilações acerca do processo que conduz a uma disseminação endógena do CT-Info no âmbito do CAU. Há todo um arcabouço de regras que norteia a submissão de projetos capazes de obter aprovação pelo comitê gestor do CT-Info. Do mesmo modo, essas regras se reproduzem ao longo dos processos de acompanhamento, prestação de contas, liberação de parcelas intermediárias e encerramento dos projetos. Sua complexidade acaba dando lugar à cristalização de uma liturgia própria na operacionalização dos projetos que dificilmente é plenamente dominada pelas PME. Ao cabo, o conjunto de conhecimentos tácitos necessários para que um empreendimento se movimente com desenvoltura no contexto de tal liturgia é, em grande medida, monopolizado pelo CAU. O resultado é a captura, constatada neste trabalho, do instrumento por parte deste complexo.

Feitas essas ressalvas, é oportuno destacar os aspectos positivos das avaliações. Durante o processo de interação com os executivos e empresários se verificou que, de modo geral, o CT-Info desempenhou um papel da maior importância - quando não absolutamente fundamental - nas trajetórias de suas empresas. Tanto as avaliações quanto os resultados concretos autorizam largamente essa conclusão. Como consequência, a relevância e a eficácia do instrumento enquanto conceitos - conforme as palavras de um dos entrevistados - no desenvolvimento tecnológico, econômico e social do país ficam evidentes. O que se deve buscar são as ações capazes de eliminar seus gargalos.

\subsubsection{SURVEY}

Para a realização desta pesquisa foram enviados e-mails para 701 empresas desenvolvedoras de software que não acessaram o CT-Info. Estes $e$-mails foram endereçados aos proprietários ou aos gestores principais das organizações. Desse total, 191 retornaram com respostas válidas, o que corresponde a 27,25\% da amostra original. Para estudos de campo com essas características, esse retorno pode ser considerado como extremamente positivo e, em se tratando de um estudo qualitativo aplicado a um grupo de indivíduos com as características da amostra utilizada, suas conclusões podem ser avaliadas como representativas.

A sondagem consistiu de uma única pergunta: por que sua organização não utiliza os créditos do CT-Info? Era possível optar por apenas uma das alternativas de resposta. Na Tabela 7 e no Gráfico 2 estão representadas a distribuição da frequência e as porcentagens de respostas para cada uma das opções.

Como se pode observar, a maioria das respostas $(53,9 \%)$ diz respeito à falta de informações acerca do fundo por parte do empresário ou gestor. Praticamente 1/4 dos pesquisados $(24,6 \%)$ declarou desconhecer o funcionamento do instrumento, enquanto 
perto de $1 / 3$ deles $(29,3 \%)$ sequer sabia da existência do CT-Info. Por esse motivo, diversos participantes acabaram buscando contato com os pesquisadores que conduziram o estudo com o intuito de obter informações acerca do instrumento.

Essa constatação torna patente a urgente necessidade de um amplo conjunto de ações de divulgação do instrumento junto ao setor produtivo, que deveria ser seu alvo principal. Os esforços que têm sido feitos nesse sentido não têm se mostrado capazes de fazer com que o CT-Info ultrapasse os muros da universidade.

Por sua vez, 9,9\% de participantes afirmaram que, mesmo tendo informações a respeito do CT-Info, julgam suas regras de operacionalização demasiadamente complexas para considerá-lo atraente. Para que se compreenda a dimensão dessa posição, é preciso não perder de vista que as respostas foram dadas por empresários (ou seus representantes) e que os créditos dos fundos setoriais caracterizam-se como financiamentos a fundo perdido, exigindo apenas contrapartidas. Em princípio sua atratividade financeira não poderia ser maior. A essas respostas somam-se outros 1,6\% que afirmaram não considerar vantajosa a relação entre custo e beneficio.

Tabela 7 - Distribuição da frequência de respostas à survey - motivos para a organização não utilizar os créditos do CT-Info

\begin{tabular}{|c|c|c|}
\hline Respostas & Qtd. & $\%$ \\
\hline Ter obtido financiamento por meio de outro fundo setorial que não o CT-Info. & 7 & 3,7 \\
\hline Não ter interesse em atividades de pesquisa, desenvolvimento, ciência e tecnologia. & 2 & 1,0 \\
\hline Não saber da existência dos fundos setoriais. & 56 & 29,3 \\
\hline $\begin{array}{l}\text { Conhecer a existência do instrumento, mas não ter conhecimento de suas regras e dinâmicas } \\
\text { de funcionamento. }\end{array}$ & 47 & 24,6 \\
\hline $\begin{array}{l}\text { Saber como o instrumento funciona, mas considerar o processo de obtenção dos recursos muito } \\
\text { complexo para se utilizar dele. }\end{array}$ & 19 & 9,9 \\
\hline $\begin{array}{l}\text { Considerar que seria viável buscar esses recursos, mas considerar, pela perspectiva de custo } \\
\text { e benefício, que não vale a pena buscá-los. }\end{array}$ & 3 & 1,6 \\
\hline $\begin{array}{l}\text { Achar que valeria a pena, mas não ter se candidatado aos créditos por não ter interesse nas atividades } \\
\text { ou linhas de pesquisa que os editais ofereciam. }\end{array}$ & 11 & 5,8 \\
\hline $\begin{array}{l}\text { Ter tido interesse nos financiamentos, mas não ter conseguido se candidatar por não ser elegível } \\
\text { segundo as regras estabelecidas nos editais. }\end{array}$ & 8 & 4,2 \\
\hline $\begin{array}{l}\text { Ter tido interesse nos financiamentos, mas não ter conseguido se candidatar por não ter conseguido } \\
\text { montar uma proposta consistente e tempestiva. }\end{array}$ & 7 & 3,7 \\
\hline $\begin{array}{l}\text { Ter tido interesse nos financiamentos, mas não ter conseguido se candidatar por não ter conseguido } \\
\text { estabelecer previamente uma parceria profícua com uma instituição de pesquisa. }\end{array}$ & 8 & 4,2 \\
\hline Ter se candidatado a financiamentos, mas não ter tido a proposta aprovada. & 14 & 7,3 \\
\hline Outras & 9 & 4,7 \\
\hline Total & 191 & 100,0 \\
\hline
\end{tabular}

Fonte: Elaboração própria. 
Essa constatação conduz à retomada da discussão acerca dos trâmites envolvidos nos processos de candidatura, acompanhamento e prestação de contas do instrumento. Verificou-se que $11,5 \%$ dos participantes se desinteressaram em virtude da complexidade dos procedimentos. Ressurge, portanto, a questão do formalismo e da burocracia que envolvem os projetos dos fundos setoriais.

\section{Gráfico 2 - Porcentagens de respostas à enquete}

Motivos para a organização não utilizar os créditos CT-INFO

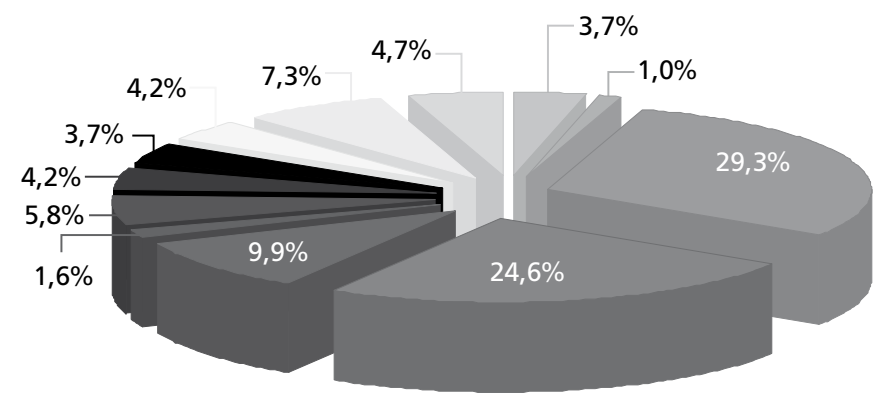

$\square 4,2 \%$ Ter obtido financiamento através de outro fundo setorial que não o CT-INFO.

$\square$ 1,0\% Não ter interesse em atividades de Pesquisa \& Desenvolvimento de Ciência \& Tecnologia.

29,3\% Não saber da existência dos Fundos Setoriais.

$\square 24,6 \%$ Conhecer a existência do instrumento, mas não ter conhecimento de suas regras e dinâmicas de funcionamento.

9,9 Saber como o instrumento funciona, mas considerar o processo de obtenção dos recursos muito complexo para se utilizar dele.

$\square 1,6 \%$ Considerar que seria viável buscar esses recursos, mas considerar, pela perspectiva de Custo X Benefício, que não vale a pena buscá-los.

$5,8 \%$ Achar que valeria a pena, mas não ter se candidatado aos créditos por não ter interesse nas atividades e/ou linhas de pesquisa o que os editais ofereciam.

$\square 4,2 \%$ Ter tido interesse nos financiamentos, mas não ter conseguido se candidatar por não ser elegível segundo as regras estabelecidas nos editais.

\3,7\% Ter tido interesse nos financiamentos, mas não ter conseguido se candidatar por não ter conseguido montar uma proposta consistente e tempestiva.

$4,2 \%$ Ter tido interesse nos financiamentos, mas não ter conseguido se candidatar por não ter conseguido estabelecer previamente uma parceria profícua com uma instituição de pesquisa.

7,3\% Ter se candidatado a financiamentos, mas não ter tido a proposta aprovada.

$4,7 \%$ Outras

Fonte: Elaboração própria.

Além dessas, três outras respostas podem ser associadas a aspectos concernentes à burocracia:

- Ter tido interesse nos financiamentos, mas não ter conseguido se candidatar por não ser elegível segundo as regras estabelecidas nos editais;

- Ter tido interesse nos financiamentos, mas não ter conseguido se candidatar por não ter conseguido montar uma proposta consistente e tempestiva; e

- Ter se candidatado a financiamentos, mas não ter tido a proposta aprovada. 
As porcentagens das respostas que indicaram essas circunstâncias como motivação foram de 4,2\%, 3,7\% e 7,3\%, respectivamente. São, portanto, mais 15,2\% a serem considerados. Somadas essas respostas às já mencionadas, chega-se a um contingente de $26,7 \%$ dos pesquisados (mais de $1 / 4$ ) que podem não ter se beneficiado do fundo em virtude de sua liturgia. Tomada apenas a parcela dos respondentes que se considera suficientemente informada a respeito do instrumento, esse grupo de empresas representa um total de 58,0\%, número consideravelmente expressivo. Além da marcação do item relativo à resposta, alguns dos formulários vieram acompanhados de comentários ou justificativas sobre a resposta assinalada. Os que se referiam a essas questões específicas apontaram enquanto obstáculo fatores relacionados ao formalismo e à burocracia. Portanto, o que se observou corrobora as conclusões resultantes da análise das entrevistas realizadas com as firmas beneficiadas.

Dificuldades no relacionamento com as instituições de pesquisa também tiveram um volume digno de registro: $4,2 \%$ do total. Fazendo-se um recorte que incorpora apenas as organizações que demonstraram ter interesse em obter o benefício, esse contingente representa uma parcela de $16,7 \%$. Nesse quesito, os comentários explicitaram dificuldades originárias da falta de uma perspectiva de mercado por parte das instituições de pesquisa.

Como última observação, registre-se que somente duas empresas, entre as 191 participantes $(1,0 \%)$ declararam não ter interesse em atividades de $\mathrm{P} \& \mathrm{D}$. Em virtude da decisão de buscar o maior número possível de participantes, ao se efetuar o desenho desse estudo, optou-se por privilegiar sua simplicidade, não se coletando informações adicionais acerca das empresas. Contudo, dada à construção da amostra utilizada, foi possível fazerem-se algumas ilações sobre suas características. Uma delas é que não devem se tratar de micro ou pequenas empresas, muito menos de firmas nascentes. Assim, os resultados dese estudo são uma importante fonte de informações para que se compreendam as barreiras que impedem o acesso ao CT-Info pelas médias empresas brasileiras - provavelmente aquelas que apresentam a melhor solução de compromisso entre a necessidade de instrumentos subsidiados e a possibilidade de realizar atividades consistentes de P\&D.

Os resultados obtidos vão ao encontro de muitas das considerações apresentadas no estudo realizado junto às organizações que tomaram parte em projetos financiados pelo CT-Info. São eles:

- Existência de uma complexa liturgia na configuração exigida para os projetos do fundo, que é monopolizada pelo complexo acadêmico-universitário;e

- Distanciamento das instituições de pesquisa das perspectivas do mundo dos negócios.

A esses, acrescenta-se a crítica falta de conhecimento acerca do instrumento por parte de seu público-alvo: o setor produtivo. 


\subsection{CONCLUSÕES}

No sentido de se elaborar um diagnóstico voltado ao aprimoramento do CT-Info, a constatação mais relevante deste estudo - particularmente em relação ao que foi definido como foco do CT-Info (Brasil/MCT, s.d.) - foi que o fundo apresenta uma limitada capacidade de ampliar a base de firmas que o utilizam, mantendo-se restrito a um círculo de organizações que, pelas suas características, se colocam como satélites do CAU.

Conforme se verificou, o conjunto de empresas que se beneficia do CT-Info, ou que a ele tem acesso, está dividido em dois grupos distintos. Um, majoritário, composto por pequenas e microempresas com relações umbilicais ao CAU; outro composto por grandes companhias com uma trajetória histórica de relacionamento com esse complexo. As pequenas empresas geradas fora do CAU e as médias empresas que nunca tiveram tal ligação (ou, se tiveram, perderam-na ao longo do tempo) parecem não possuir as mesmas facilidades de acesso ao instrumento de fomento. Em outras palavras, o que se depreende é que o CT-Info ainda não foi capaz de ultrapassar os limites da universidade. As causas mais visíveis desse comportamento endógeno, de captura do CT-Info pelo CAU, são deficiências na divulgação e uma série de procedimentos complexos, formais e burocráticos em sua execução. Essa situação se traduz na baixíssima participação de médias empresas, que seriam as que provavelmente reúnem as melhores condições para que o instrumento produza as externalidades desejáveis e que estão, aparentemente, ávidas por esse tipo de apoio. Esse quadro resulta em que não se cumpra em sua plenitude o objetivo de acelerar o processo de desenvolvimento impulsionando-o por intermédio da "hélice tríplice" formada por Estado, universidade e empresa (Etzkowitz, 2009).

Há, ainda, a hipótese de que a relação causal seja exatamente a inversa. Isto é, que todos os fatores assinalados sejam, na verdade, uma consequência da captura do instrumento pelo CAU, surgindo como um desdobramento natural do fenômeno. Ou até mesmo enquanto um conjunto de mecanismos sistêmicos destinados exatamente a assegurar esta captura e preservar seu monopólio. Porém, o que parece ser mais provável é a existência de um círculo vicioso, isto é, de uma situação induzida por um processo reflexivo, na qual as duas dinâmicas se coalimentam.

É evidente que, a partir de um estudo dessa natureza, é temerário que se façam generalizações, porquanto seu objeto restringiu-se a um setor específico de um único instrumento. Todavia, os resultados obtidos sugerem a necessidade de uma profunda reflexão sobre as políticas públicas de desenvolvimento, permitindo que se formule uma hipótese que merece investigação mais ampla: a de que as tradicionais políticas de desenvolvimento, baseadas fundamentalmente em instrumentos creditícios e tributários, são restritas em sua capacidade de incentivo, uma vez que não incorporam, ao processo, novos agentes econômicos, mas se limitam a facilitar a ação daqueles que já são atores naquele contexto ou que apresentam elevado potencial para vir a sê-lo. 


\section{CONSIDERAÇÕES FINAIS}

As políticas públicas avaliadas neste artigo apontam para resultados bastante similares. As análises apresentadas sugerem que, de forma geral, os incentivos à inovação e à exportação selecionados neste trabalho beneficiam empresas que já realizam atividades de exportação, $\mathrm{P} \& \mathrm{D}$ ou desenvolvimento tecnológico. Os instrumentos não parecem capazes de ampliar a base de empresas engajadas nessas atividades. Não demonstram eficácia na disseminação de tais práticas por todo o conjunto da economia, sendo capturados por segmentos específicos de seus diversos setores. Haveria, portanto, um círculo vicioso no qual um limitado grupo de empresas se beneficia dos instrumentos exatamente por já adotarem anteriormente as práticas que tais instrumentos objetivam promover. Em outras palavras, ao invés de incentivar empresas a adotarem as práticas em questão, os instrumentos se limitam a facilitar a operação daquelas que já as adotavam.

Desse modo, o objetivo central do texto foi questionar a endogeneidade das políticas de incentivo à exportação e inovação no Brasil, dado que estas acabam estimulando os agentes que, em sua maioria, já são exportadores ou inovadores. Ao invés de incentivar novos agentes a exportar ou inovar, o que se observa é um efeito contrário: agentes que já investem em exportação ou inovação acabam capturando tais recursos. É a essa conclusão central do texto que o título se reporta: incentivo leva à exportação/ inovação, ou inovadores/exportadores captam o incentivo?

Tais conclusões, ainda que preliminares e demandantes de aprofundamento, e de avaliações similares de outros instrumentos, servem como ponto de partida para a formulação das hipóteses explicativas. Uma das hipóteses mais evidentes é a de que os instrumentos tradicionais, baseados em créditos e incentivos fiscais, têm uma capacidade de abrangência limitada, existindo barreiras que impedem que um contingente mais significativo de empresas faça uso deles. Essas barreiras podem caracterizar-se por aspectos ligados ao tamanho, à dicotomia formalidade e informalidade dos negócios, à burocracia (ou liturgia) que envolve a utilização desses instrumentos, ou mesmo a um nível de desenvolvimento de tecnologia de gestão não alcançado pela maior parte das empresas, especialmente as PME, necessário até para que as empresas compreendam a importância desses fatores para o seu crescimento e sustentação.

Tal hipótese sugere que, para o país alcançar os patamares desejados de desenvolvimento, crescimento e produtividade, os instrumentos existentes devam ser redefinidos. Ou então, novos instrumentos de políticas públicas, de natureza diversa dos que hoje são empregados, direcionados (adequados) especificamente para outros agentes da economia, e que sejam complementares aos já existentes, devam ser desenhados. 


\section{REFERÊNCIAS BIBLIOGRÁFICAS}

AVELLAR, A. P. Avaliação do impacto do PDTI sobre o gasto em atividades de inovação e em P\&D das empresas industriais. In: DE NEGRI, F.; KUBOTA, L. (Orgs.) Políticas de incentivo à inovação tecnológica no Brasil. Brasília: IPEA, 2008.

BANCO CENTRAL DO BRASIL (BCB). Base de microdados. Brasília: BCB, 2006.

BANCO NACIONAL DE DESENVOLVIMENTO ECONOMICO E SOCIAL (BNDES). Base de microdados. Rio de Janeiro: BNDES, 2009.

BRASIL. Ministério da Ciência e Tecnologia. Relatório anual da utilização dos incentivos fiscais: ano base 2008. Brasília: MCT, nov., 2009. Disponível em: <http://www.mct.gov.br >. Acesso em: 24 abr. 2013.

BRASIL. Ministério da Ciência e Tecnologia. Fundos Setoriais - FNDCT: fundo setorial de tecnologia da informação - CT-Info. [s.d.]. Disponível em: <http://www.mct.gov.br/index. php/content/view/1413.html>. Acesso em: 19 jan. 2010.

BRASIL. Ministério do Desenvolvimento, Indústria e Comércio Exterior. Inovar e investir para sustentar o crescimento: íntegra da apresentação da política de desenvolvimento produtivo (PDP). Brasília: MDIC, [s.d.]. Disponível em: <http://www.mdic.gov.br/pdp/arquivos/ destswf1212175349.pdf>.

CORDER, S. Políticas de inovação tecnológica no Brasil: experiência recente e perspectivas. Texto para Discussão, IPEA, n. 1.244, dez., 2006.

ETZKOWITZ, H. Hélice tríplice: universidade - indústria - governo. Porto Alegre: EDIPUCRS, 2009.

GRECO, S. M. S. S. ET AL. Empreendedorismo no Brasil: 2008. Curitiba: IBQP, 2009. Disponível em: <http://www.biblioteca.sebrae.com.br/bds/bds.nsf/5D1CAC412448B0428325757B006 97DC7/\$File/NT0003EF2A.pdf>. Acesso em: 20 mar. 2010.

GRIMALDI, D.; CARNEIRO, F. Avaliação de políticas públicas de promoção de exportação: uma análise de micro-dados para o Exim, Proex e Drawback entre 2003 e 2007. In: ACIOLY, L.; CINTRA, M. A. M. (Orgs.) Inserção internacional brasileira: temas de economia internacional. Livro 3, Vol. 2. Brasília: IPEA, 2010. Disponível em: <http://www.ipea.gov.br/portal/index. php?option $=$ com_content $\& v i e w=$ article\&id $=6469>$. Acesso em: 6 de maio de 2013

GUIMARÃES, E. Políticas de inovação: financiamento e incentivos. Texto para Discussão, IPEA, n. 1.212, ago. 2006.

INSTITUTO BRASILEIRO DE GEOGRAFIA E ESTATÍSTICA (IBGE). Pesquisa Industrial 2003: empresa. Rio de Janeiro: IBGE, 2003. Disponível em: <http://www.ibge.gov.br/home/ estatistica/economia/industria/pia/empresas/emp2003.pdf>. Acesso em: 24 abr. 2013.

INSTITUTO BRASILEIRO DE GEOGRAFIA E ESTATÍSTICA (IBGE). Pesquisa de inovação tecnológica (PINTEC). Rio de Janeiro: IBGE, 2005. Disponível em: <http://www.ibge.gov.br/ home/estatistica/economia/industria/pintec/2005/pintec2005.pdf>. Acesso em: 24 abr. 2013. 
KANNEBlEY JÚNIOR, S.; ESTEVES, L. A.; SILVA, A. M. P.; ARAUJO, B. C. Padrões microeconômicos de comércio internacional e a estratégia brasileira de exportação. Texto para Discussão, IPEA, n. 1.473, 2010.

MATESCO, V. R.; TAFNER, P. O estímulo aos investimentos tecnológicos: o impacto sobre as empresas brasileiras. Pesquisa e Planejamento Econômico, Rio de Janeiro, v. 26, n. 2, p. $307-$ 332, ago., 1996.

MINISTÉRIO DO DESENVOLVIMENTO INDÚSTRIA E COMÉRCIO EXTERIOR (MDIC). Base de microdados de comércio exterior. Brasília: MDIC, 2009.

MOREIRA, N.; ALMEIDA, F. A. S.; COTA, M. F. M.; SBRAGIA, R. A inovação tecnológica no Brasil: os avanços no marco regulatório e a gestão dos fundos setoriais. Revista de Gestão USP, São Paulo, v. 14, n. especial, p. 31-44, 2007.

MINISTÉRIO DO TRABALHO E EMPREGO (MTE). Base de microdados RAIS. Brasília: MTE, 2009

NOGUEIRA, M.; KUBOTA, L.; MILANI, D. CT-Info: uma visão a fundo. Revista Brasileira de Inovação, v. 2, n. 10, jul./dez., 2011.

SERVIÇO BRASILEIRO DE APOIO ÀS MICRO E PEQUENAS EMPRESAS (SEBRAE). Fatores condicionantes e taxas de sobrevivência e mortalidade das micro e pequenas empresas no Brasil: 2003-2005. Brasília: SEBRAE, 2007. Disponível em: <http://www.biblioteca.sebrae. com.br/bds/bds.nsf/8F5BDE79736CB99483257447006CBAD3/\$File/NT00037936.pdf >. Acesso em: 23 abr. 2013.

UNITED NATIONS CONFERENCE ON TRADE AND DEVELOPMENT (UNCTAD). World investment report: transnational corporations and the internationalization of R\&D. cap. 6 . New York; Geneva: UNCTAD, 2005.

ZUCOLOTO, G. F. Lei do Bem: impactos nas atividades de P\&D no Brasil setoriais. Radar, IPEA, n. 6, fev., 2010. 